\title{
Modification of Fatty Acid Composition of the Phospholipids of Cultured Rat Ventricular Myocytes and the Rate of Phosphatidylinositol-4,5-Bisphosphate Hydrolysis
}

\author{
Jos M.J. Lamers, Dick H. W. Dekkers, Netty De Jong and Johanna T. A. Meij* \\ Department of Biochemistry, Faculty of Medicine and Health Sciences, Erasmus University Rotterdam, \\ Rotterdam, The Netherlands
}

(Received 18 February 1991, accepted in revised form 9 January 1992)

\begin{abstract}
J. M.J. Lamers, D. H. W. Dexkers, N. De Jong, And J. T. A. Meij. Modification of Fatty Acid Ciomposition of the Phospholipids of Cultured Rat Ventricular Myocytes and the Rate of Phosphatidylinositol-4,5-Bisphosphate Hydrolysis. Journal of Molecular and Cellular Cardiology (1992) 24, 605-618. Cultured neonatal cardiac myocytes have been utilized as a model for the study of the role of fatty acids in the $\alpha_{1}$-adrenoceptor mediated phosphatidylinositol turnover. Experiments were started $24 \mathrm{~h}$ after seeding, when there was a confluent monolayer of beating cardiomyocytes. The cells were incubated for 3-4 days in sera containing culture inedium with (1) no additives or (2) a mixture of $107 \mu \mathrm{M} 18: 0$ and $18: 1 n-9$, or (3) only $214 \mu \mathrm{M} 18: 2 n-6$ or (4) $214 \mu \mathrm{M}$ $20: 5 n-3$. No differences in the cellular content of the various phospholipid classes among the different groups of fatty acid treated cells were found. The predicted elevations of $18: 1 n-9,18: 2 n-6$ and $20: 5 n-3$ associated with a partial depletion of 20:4n-6 were confirmed in all phospholipid classes, except for sphingomyelin. The mol \% of 18:0, 18:2n-6, 20:4n-6 and 20:5n-3 in the phosphatidylinositol fraction were respectively $39,4,30$ and 0.6 for the control treated cells, $34,3,15$ and 0 for 18:0/18:1n-9 treated cells, $40,17,24$ and 0.2 for the $18: 2 n-6$ treated cells and $41,3,13$ and 21 for the 20:5n-3 treated cells. Apart from the observed reductions in the basal rates, the phenylephrine $(30 \mu \mathrm{M})$ stimulated production of inositolphosphates was reduced by $51 \%$ and $71 \%$, respectively in the 18:2n-6 and 20:5n-3 treated cardiomyocytes. The basal rate of inositolphosphate formation was $37 \%$ increased in the 18:0/18:1n-9 treated cells. The $\left[{ }^{3} \mathrm{H}\right]$-inositol incorporation into phosphatidylinositol 4,5-bisphosphate was only slightly reduced by $18: 2 n-6$ and $20: 5 n-3$ treatments (respectively 12 and $28 \%$ compared to control treated cells). Prolonged ( $30 \mathrm{~min}) \alpha_{1}$-adrenergic stimulation did not affect the contents and fatty acid profiles of any class of phospholipid, not even phosphatidylinositol. In conclusion, variations in the polyunsaturated fatty acid composition of membrane phospholipids do affect the basal and the $\alpha_{1}$-adrenoceptor stimulated rate of phosphatidylinositol-4,5-bisphosphate hydrolysis. The reducing effects of $18: 2 n-6$ and $20: 5 n-3$ treatment on the rate of inositolphosphate production may be partially ascribed to altered levels of phosphatidyl. inositol 4,5-bisphosphate.
\end{abstract}

KEY WORDS: Cultured cardiomyocytes; $\boldsymbol{\alpha}_{1}$-adrenergic receptors; Polyunsaturated fatty acids; Phospholipids; Phosphatidylinositol; Linoleic acid; Eicosapentaenoic acid; Phosphatidylinositol cycle; Fatty acid chain elongation; Triacylglycerides; Lipolysis; Protein kinase C.

\section{IIntroduction}

The fatty acyl composition of cell membranes can be markedly altered by dietary means, especially by changing the degree of polyunsaturation. For this reason it is important to understand the consequences of such modification in terms of membrane phospholipid dynamics and function. Dietary $n-3$ polyunsaturated fatty acids ( $n-3$ PUFA) have been shown to result in a reduction of the $\alpha_{1}$ - but

\footnotetext{
${ }^{1}$ Abbreviations: PC, phosphatidylcholine; PE, phosphatidylethanolamine; PI, phosphatidylinositol; PS, phosphatidylserine; SPM, sphingomyelin; NEFA, non-esterified fatty acids; PIP, phosphatidylinositol-4-monophosphate; PIP ${ }_{2}$, phosphatidylinositol-4,5-bisphosphate; $\mathrm{IP}_{\mathrm{n}}$, inositolphosphates; $\mathrm{IP}_{1}$, inositolmonophosphate; $\mathrm{IP}_{2}$, inositolbisphosphate; $\mathrm{IP}_{3}$, inositoltrisphosphate; $18: 0$, stearic acid; $21: 0$, heneicosanoic acid; $18: 1$, oleic acid; $18: 2 n-6$, linoleic acid; 20:4n-6, arachidonic acid; $20: 5 n-3$, eicosapentaenoic acid; $22: 5 n-3$, docosapentaenoic acid; $22: 6 n-3$, docosahexaenoic acid; PUFA, polyunsaturated fatty acids; DG, diacylglycerides; TG, triacylglycerides; TLC, thin-layer chromatography; BHT, butylated hydroxytoluene.

${ }^{*}$ Present address: Division of Cardiovascular Sciences, St. Boniface G.H. Research Centre, University of Manitoba, Winnipeg, Manitoba, Canada.

Please address all correspondence to: J.M.J. Lamers, Department of Biochemistry I, Faculty of Medicine and Health Sciences, Erasmus University Rotterdam, P.O. Box 1738, 3000 DR ROTTERDAM, The Netherlands.
} 
not of the $\beta$-adrenoceptor mediated changes in cardiac inotropy (Reibel et al., 1988) and so the question arises whether the difference in the $\alpha_{1}$-adrenergic response after incorporation of those PUFA into heart membranes is caused by alterations in the rate of phosphatidylinositol-4,5-bisphosphate $\left(\mathrm{PIP}_{2}\right)$ breakdown by specific phospholipase $\mathrm{C}$. A massive incorporation of eicosapentaenoic acid $(20: 5 n-3)$ and docosahexaenoic acid $(22: 6 n-3)$ at the expense of linoleic acid $(18: 2 n-6)$ and arachidonic acid (20:4n-6) was observed in the cardiac total phospholipid fraction from rats fed with $n-3$ PUFA (Reibel et al., 1988). Changes in platelet responsiveness to aggregating substances induced by intervention with dietary $n-3$ PUFA have usually been related to alterations in the production of eicosanoid precursor fatty acids and not merely to alterations in the fatty acid composition of membrane phospholipids (Hartog et al., 1987; Lamers et al., 1987 and Leaf and Weber, 1988). However, Medini et al. (1990) demonstrated that dietary 20:5n-3 modulated the pathway of inositol-1,4,5-trisphosphate $\left(\mathrm{IP}_{3}\right)$ generation in platelets from rabbits independent of modification of thromboxane production. Likewise, Reibel et al. (1988) showed that changes in eicosanoid production induced by dietary fish oil were not likely involved in the attenuation of the myocardial $\alpha_{1}$-adrenoceptor response.

In vivo studies (Gudbjarnason et al., 1978 and Montfoort et al., 1986) have indicated that chronic noradrenaline stress produces changes in $n$ - 3 relative to the $n-6$ PUFA content of myocardial phospholipids, particularly that of the phosphatidylethanolamine fraction. It is not known whether this noradrenaline treatment effect is a direct $\alpha_{1}$ - or $\beta$-adrenergic effect on the myocardial cells or an indirect $\alpha_{1}$ or $\beta$-adrenergic effect resulting from altered lipid metabolism in the liver. Nevertheless, the accelerated turnover of the myocardial (polyphospho)PI lipids, induced by $\alpha_{1}$ adrenoceptor stimulation, could be one of the factors involved in the in vivo effects of noradrenaline stress on myocardial phospholipids.

Several reports have described that the fatty acid composition of culture cardiomyocytes can be modified by addition of non-esterified fatty acids (NEFA) to the culture medium
(Grynberg et al., 1988; Meij et al., 1990; Nalbone et al., 1990; Hallaq et al., 1990). These cells, isolated from neonatal rat hearts, beat spontaneously with a regular rhythm and amplitude of contraction and can be incubated free from circulating agonists (Meij and Lamers, 1989a and b). They maintain their function for several days in culture medium, which allows time for incorporation of longchain (polyunsaturated) fatty acids into the phospholipids of their cell membranes. Recently, we showed that $20: 5 n-3$ as well as $18: 2 n-6$ treatment of cultured heart cells had no effect on the basal and $\alpha_{1}$-adrenoceptor stimulated $\mathrm{PIP}_{2}$ hydrolysis (Meij et al., 1990). However, in this study only minor changes occurred in fatty acid composition of the phospholipids (e.g. the maximal $n-3 / n-6$ PUFA molar ratio amounted 0.45 ). Nalbone et al. (1990) showed increases of the $n-3 / n-6$ PUFA molar ratio up to 1.1 in cultured cardiomyocytes, very near to values reported in the study of Reibel et al. (1988).

In the present study, we investigated the effect of NEFA supplements to the serum in the primary culture of rat cardiomyocytes on the fatty acid composition of the various phospholipid classes, with particular attention to the PI fraction. The main object was to observe the influence of these changes on the rate of basal and $\alpha_{1}$-adrenoceptor mediated $\mathrm{PIP}_{2}$ hydrolysis. We also evaluated the possible effects of long-term $\alpha$-adrenergic stimulation of the PI turnover on the fatty acid composition of the PI fraction as well as all the other phospholipid classes.

\section{Materials and Methods}

\section{Chemicals}

Growth medium: Nutrient mixture Ham F10 (Gibco, Scotland) supplemented with $10 \% \mathrm{v} / \mathrm{v}$ fetal calf serum, $10 \% \mathrm{v} / \mathrm{v}$ horse serum, 200 $\mathrm{U} / \mathrm{ml}$ penicillin, $0.2 \mathrm{mg} / \mathrm{ml}$ streptomycin (all from Boehringer, Mannheim, FRG) and 135 $\mu \mathrm{g} / \mathrm{ml} \mathrm{CaCl}{ }_{2} .2 \mathrm{H}_{2} \mathrm{O}$; Petri dishes (TC $35 / 10$ and TC 60/15) were from Greiner (Nürtingen, FRG); four-well multidishes were from Nunc (Denmark); trypsin (type III) was from Sigma as were the $18: 1 n-9,18: 2 n-6$ and $20: 5 n-3$, the $\mathrm{BF}_{3} /$ methanol and the lipid standards phosphatidylcholine (PC), phospha- 
tidylethanolamine (PE), phosphatidylinositol (PI), phosphatidylserine (PS), sphingomyelin (SPM) and lysophosphatidylcholine; 18:0 was from BDH (Poole, England); standard fatty acid methylesters and the internal standard heneicosanoic acid (21:0) for the transmethylation reaction were from Alltech Ass., Inc (Deerfield, USA); $\left[2-{ }^{3} \mathrm{H}\right]$-myoinositol was from Amersham International PLC (Amersham, UK); [dipalmitoyl-1-1 $\left.{ }^{14} \mathrm{C}\right]-\mathrm{PC}$ and EN ${ }^{3}$ HANCE spray were from NEN (Boston, USA); phenylephrine $\mathrm{HCl}$ was from Brocades (Delft, The Netherlands); Thin layer chromatography plates (Kieselgel 60 F-254) were from Merck (Darmstadt, FRG), Dowex 1-X8 (100-200 mesh, formate form) from BioRad Labs (California, USA) and Instagel was from Packard (Groningen, The Netherlands); Triacylglyceride and glycerol test kits (respectively, GPO-PAP and Precimat $^{\oplus}$ glycerol) were from Boehringer
(Mannheim, FRG). All other chemicals were of analytical grade.

\section{Primary heart cell culture}

Cardiomyocytes were isolated from the ventricles of 2-4-day-old Wistar rats by trypsinization and grown according to Yagev et al. (1984). We applied a modified enrichment method of two successive periods of 30 and 90 min plating (Blondel et al. (1971); Meij and Lamers (1989a and b)). Of the final suspension containing $9 \times 10^{5}$ myoblasts per $\mathrm{ml}, 2 \mathrm{ml}$ were seeded per TC $35 / 10$ Petri dish, $6 \mathrm{ml}$ per TC $60 / 15$ Petri dish and $0.6 \mathrm{ml}$ per well in 4-well multidishes. After $24 \mathrm{~h}$ incubation $\left(37^{\circ} \mathrm{C}, 5 \% \mathrm{CO}_{2}, 95 \%\right.$ humidity) this resulted in a confluent monolayer of beating cardiomyocytes. About $24 \mathrm{~h}$ after seeding the growth medium was replaced by conditioned medium (Table 1).

TABLE 1 Total and non-esterified fatty acid content $(\mu \mathrm{M})$ of the conditioned media

\begin{tabular}{|c|c|c|c|c|c|c|c|c|}
\hline \multirow{2}{*}{$\begin{array}{l}\text { Fatty } \\
\text { acid }\end{array}$} & \multicolumn{2}{|c|}{ Control } & \multicolumn{2}{|c|}{$18: 0 / 18: 1 n-g$} & \multicolumn{2}{|c|}{$18: 2 n-6$} & \multicolumn{2}{|c|}{$20: 5 n-3$} \\
\hline & $\begin{array}{c}\text { Total } \\
\mu \mathrm{M}\end{array}$ & $\begin{array}{c}\mathrm{NEFA}^{\mathrm{b}} \\
\mu \mathrm{M}\end{array}$ & $\begin{array}{l}\text { Total } \\
\Delta \mu M^{e}\end{array}$ & $\begin{array}{c}\text { NEFA } \\
\Delta \mu \mathrm{M}\end{array}$ & $\begin{array}{l}\text { Total } \\
\Delta \mu \mathrm{M}\end{array}$ & $\begin{array}{c}\text { NEFA } \\
\Delta \mu \mathrm{M}\end{array}$ & $\begin{array}{l}\text { Total } \\
\Delta \mu \mathrm{M}\end{array}$ & $\begin{array}{c}\text { NEFA } \\
\Delta \mu \mathrm{M}\end{array}$ \\
\hline $16: 0$ & 221 & 9.8 & 7 & 0.5 & -2 & -0.5 & 6 & -0.2 \\
\hline $18: 0$ & 226 & 5.9 & 80 & 104 & -33 & -0.8 & -10 & -0.2 \\
\hline $18: 1 n-9$ & 221 & 7.5 & 125 & 104 & -3 & -0.1 & 18 & 0.6 \\
\hline $18: 2 n-6$ & 410 & 5.9 & -5 & 0 & 208 & 218 & -11 & -0.1 \\
\hline $20: 4 n-6$ & 19.4 & 0.2 & 0.7 & 0 & 3.2 & 0.1 & 2.7 & 0.1 \\
\hline $20: 5 n-3$ & n.d. ${ }^{d}$ & n.d. & n.d. & n.d. & n.d. & n.d. & 201 & 215 \\
\hline $22: 5 n-3$ & 5.2 & n.d. & 0.1 & n.d. & 0.1 & n.d. & 0.6 & n.d. \\
\hline $22: 5 n-6$ & 6.5 & n.d. & 0.9 & n.d. & 1 & n.d. & 1.2 & n.d. \\
\hline EPUFA $^{c}$ & 441 & 6.1 & -3 & 0 & 211 & 218 & 215 & 215 \\
\hline
\end{tabular}

a Fatty acid content of the culture medium containing fatty acids esterified in phospholipids, cholesterolesters, TG and NEFA.

bNEFA stands for the non-esterified fatty acid fraction.

' $\Sigma$ PUFA is the sum of PUFA.

$d_{\text {n.d. means non-detectable. }}$

${ }^{e} \Delta \mu \mathrm{M}$ is the change of total fatty acid or NEFA concentration versus control medium. The data represent the mean of duplicate measurements.

\section{Cell incubations}

At the beginning of each experiment the batch of dishes was divided into four sets, each set receiving one of the following conditioned media: (1) control medium; (2) 18:0/18:1n-9 rich medium which was supplemented with 18:0 and 18:1n-9, $107 \mu \mathrm{M}$ each; (3) 18:2n-6 rich medium which was supplemented with $214 \mu \mathrm{M}$ $18: 2 n-6$; (4) $20: 5 n-3$ rich medium which was supplemented with $214 \mu \mathrm{M}$ 20:5n-3 (Table 1). The ethanolic fatty acid solutions were mixed under vigorous stirring with the concentrated calf and horse sera (containing excess of fatty acid poor albumin molecules) followed by 
addition of the Ham F10 medium. Because the non-esterified fatty acids (NEFA) were dissolved in ethanol when added to the sera during preparation of each medium, control medium contained an equal concentration $(0.3 \% \mathrm{v} / \mathrm{v})$ of pure ethanol. Fresh conditioned media were given to each set after $65 \mathrm{~h}$. Furthermore every medium was supplemented with either $88 \mathrm{nM}$ unlabelled myoinositol or - to study $\left[{ }^{3} \mathrm{H}\right]$-inositolphosphate formation $-88 \mathrm{nM}\left[2-{ }^{-3} \mathrm{H}\right]$-myoinositol $(2 \mu \mathrm{Ci} /$ $\mathrm{ml})$. The dishes were then incubated with those fresh media for at least $24 \mathrm{~h}\left(37^{\circ} \mathrm{C}, 5 \%\right.$ $\mathrm{CO}_{2}, 95 \%$ humidity) before starting the cell stimulation. In the $\left[{ }^{3} \mathrm{H}\right]-\mathrm{IP}_{\mathbf{n}}$ formation studies small dishes (type 35/10) were used and for the lipid and fatty acid analysis large dishes (type $60 / 15)$ were used. For the study of $\left[{ }^{3} \mathrm{H}\right]$-inositol incorporation into PI, PIP and $\mathrm{PIP}_{2}$ 4-well multidishes were used.

\section{Cell stimulation and assay of $\left[{ }^{3} \mathrm{H}\right]$-inositolphosphates}

After $24 \mathrm{~h}$ preincubation of the cardiomyocytes with $\left[{ }^{3} \mathrm{H}\right]$-myoinositol in the conditioned culture medium, the dishes were rinsed twice with $1 \mathrm{ml}$ buffer $(130 \mathrm{mM} \mathrm{NaCl}$, $4.7 \mathrm{mM} \quad \mathrm{KCl}, \quad 1.3 \mathrm{mM} \quad \mathrm{CaCl}_{2}, \quad 20 \mathrm{mM}$ $\mathrm{NaHCO}_{3}, \quad 0.44 \mathrm{mM} \quad \mathrm{NaH}_{2} \mathrm{PO}_{4}, \quad 1.1 \mathrm{mM}$ $\mathrm{MgCl}_{2}, 0.2 \%$ w/v glucose, $\mathrm{pH} 7.4$, equilibrated at $37^{\circ} \mathrm{C}$ with $5 \% \quad \mathrm{CO}_{2}$ at $9 ? \%$ humidity) and the cells were equilibrated in this buffer for $30 \mathrm{~min}$. Then $\mathrm{LiCl}$ was added to a final concentration of $10 \mathrm{mM}$. After another $10 \mathrm{~min}$ of preincubation, phenylephrine at a final concentration of $30 \mu \mathrm{M}$, or buffer was added to a final volume of $1 \mathrm{ml}$. Incubations were terminated after $30 \mathrm{~min}$ by rinsing the small dishes with $0.5 \mathrm{ml}$ cold buffer followed by the addition of $0.5 \mathrm{ml}$ cold methanol $/ 12 \mathrm{M}$ $\mathrm{HCl}(100: 1, \mathrm{v} / \mathrm{v})$. The cells were scraped using a rubber policeman and the suspension was collected in a glass tube. The dish was rinsed once more with $0.5 \mathrm{ml}$ of methanol $/ 12 \mathrm{M} \mathrm{HCl}$, which was transferred to the same glass tube. Then $1 \mathrm{ml}$ chloroform and $0.5 \mathrm{ml} 2.5 \mathrm{M} \mathrm{HCl}$ were added to the tube. After centrifugation (10 min, $1550 \mathrm{~g}$ ) the upper phase, containing the $\mathrm{IP}_{\mathrm{n}}$, was collected and the lower phase was washed once with $1.5 \mathrm{ml}$ methanol/chloroform/0.6 M HCl (48:3:47, v/v/v). The upper phases were combined and $5 \mathrm{ml}$ distilled water was added. The $I P_{n}$ were separated by anion exchange using $1 \mathrm{ml}$ Dowex $1-\mathrm{X} 8$ according to the method of Berridge et al. (1982). Briefly, free inositol and glycerophosphoinositides were eluted with $10 \mathrm{ml}$ distilled water and $10 \mathrm{ml} 5 \mathrm{mM}$ disodiumtetraborate in $30 \mathrm{mM}$ sodiumformate respectively. Inositolmonophosphate (IP), inositolbisphosphate ( $\left.\mathrm{IP}_{2}\right)$ and inositoltrisphosphate $\left(\mathrm{IP}_{3}\right)$ were eluted all together using $10 \mathrm{ml} 1.0 \mathrm{M}$ ammonium formate in $0.1 \mathrm{M}$ formic acid. One volume of the eluate was mixed with one volume of Instagel and counted for radioactivity by liquid scintillation (Tri-carb 2660, from Packard, Groningen, The Netherlands).

\section{Separation of lipids and quantification of fatty acid methylesters}

For studying the incorporation of $\left[{ }^{3} \mathrm{H}\right]$-inositol into PI, PIP and PIP $_{2}$ of control and fatty acid treated cardiomyocytes, cells from 4-well multidishes were rinsed twice with $0.5 \mathrm{ml}$ icecold Ham F10 medium without sera. Thereafter the cells were scraped off and extracted with the methanol/ $\mathrm{HCl}$ procedure (Meij and Lamers, 1989b). The washed lower organic phase was evaporated to dryness with $\mathrm{N}_{2}$, redissolved and spotted on TLC plates previously impregnated with $1 \%$ potassiumoxalate in methanol $/ \mathrm{H}_{2} \mathrm{O}(2: 3, \mathrm{v} / \mathrm{v})$ and activated for $30 \mathrm{~min}$ at $110^{\circ} \mathrm{C}$. The plates were developed as previously described (Meij and Lamers, 1989b). After development the plates were dried and sprayed with $\mathrm{EN}^{3} \mathrm{HANCE}$ to visualize the radioactive spots by fluorography (Kodak SB5). The different inositol containing spots, identified by co-elution of authentic standard (polyphospho)PI lipids, were scraped off and counted for radioactivity by liquid scintillation.

For studying the lipid composition of the treated unlabelled cells, the cell incubations containing unlabelled myoinositol were terminated after $30 \mathrm{~min}$ by rinsing the large dishes with $1.5 \mathrm{ml}$ cold buffer, followed by the addition of $1.5 \mathrm{ml}$ cold methanol. The cells were scraped using a rubber policeman and the suspension was collected in a glass tube. The dish was then rinsed again with $1.5 \mathrm{ml}$ of methanol. After addition of $1.5 \mathrm{ml}$ chloroform, the suspension was stored under nitrogen at $-20^{\circ} \mathrm{C}$ overnight. For the estimation 
of the recovery of total phospholipids, tracer amounts of $\left[{ }^{14} \mathrm{C}\right]-\mathrm{PC}$ were added. The phases were then separated by adding chloroform and $0.1 \mathrm{M} \mathrm{KCl}$ to a final ratio of $2: 2: 1(\mathrm{v} / \mathrm{v} / \mathrm{v})$ and centrifugation (10 $\mathrm{min}, 1550 \mathrm{~g}$ ), according to Bligh and Dyer (1959). The organic lower phases of the two extracts were combined.

Approximately $0.40-0.75 \mathrm{ml}$ of the combined lipid extracts were used for the separation of total phospholipid and TG fractions from other lipids by thin layer chromatography, using activated plates and hexane/diethylether/acetic acid $(60: 40: 1, \mathrm{v} / \mathrm{v} / \mathrm{v})$ as solvent system and $0.02 \% \mathrm{w} / \mathrm{v}$ butylated hydroxytoluene (BHT) as an antioxidant. The phospholipid spot remaining at the origin was scraped off and extracted twice with $1.5 \mathrm{ml}$ methanol.

For the separation of various phospholipid classes, about $5 \mathrm{ml}$ of the combined extracts were evaporated to dryness with $\mathrm{N}_{2}$ at $37^{\circ} \mathrm{C}$ and redissolved in a small volume of organic solvent. The samples were applied under $\mathrm{N}_{2}$ to an activated $\left(30 \mathrm{~min}, 110^{\circ} \mathrm{C}\right) \mathrm{TLC}$ plate. The plates were developed with the solvent chloroform/methanol/petroleum ether (bp 40$\left.60^{\circ} \mathrm{C}\right) /$ acetic acid/boric acid (40:20:30: $14: 1.8, \mathrm{v} / \mathrm{v} / \mathrm{v} / \mathrm{vw})$ containing $0.02 \%(\mathrm{w} / \mathrm{v})$ BHT by a modified method - Tilfillan $e t$ al. (1983). The spots were visualized by spraying with Rhodamine 6G $(0.01 \%)$. The individual phospholipids were identified by co-migration of standards. The plate was dried under $\mathrm{N}_{2}$ and the scraped spots were extracted twice with $1.5 \mathrm{ml}$ methanol for fatty acid analysis.

After addition of $20 \mathrm{nmol}$ of the internal standard 21:0 to the extracted phospholipid fractions, the methanol was evaporated under $\mathrm{N}_{2}$ and the phospholipids were transmethylesterified using $\mathrm{BF}_{3}$ as previously described by Morrison and Smith (1964). For the gas chromatographic separation of the fatty acid methyl esters a CP9000 capillary column chromatograph (Chrompack, Middelburg, The Netherlands), equipped with a CP-Sil 88 coated fused silica capillary column, was used. The separated peaks were identified on the basis of the retention times as compared to standards (Montfoort et al., 1986).

\section{Analysis of $T G$ and glycerol}

TG was measured spectrophotometrically in the initial lipid extracts using the test kit. For the study of glycerol release, the incubation media were collected just before the wash step at the end of the cell incubations. Glycerol was measured fluorimetrically according to the method of Laurell and Tibbling (1966).

\section{Statistical analysis}

All data are expressed as means \pm S.E.. Multiple comparisons were made between control and fatty acid treated cells by unpaired Student's $t$-test with $P<0.05$ being considered significant.

\section{Results}

Fatty acid composition of membrane phospholipids

The effects on membrane composition were examined in cardiomyocytes isolated from neonatal rats that were incubated for 3-4 days in animal sera containing culture medium with (1) no additives or (2) a mixture of $107 \mu \mathrm{M} 18: 0$ and $107 \mu \mathrm{M} 18: 1 n-9$, or (3) only $214 \mu \mathrm{M} 18: 2 n-6$ or (4) $214 \mu \mathrm{M}$ 20:5n-3. Table 1 shows the total fatty acid and NEFA content in $\mu \mathrm{M}$ of the four conditioned media. Supplementation of the media with NEFA changed the total fatty acid content of the media only moderately (not more than $20 \%$ increase). The total pool of fatty acids is mainly composed of those esterified in TG, cholesterolesters and phospholipids which are all present in the lipoproteins of the added sera. However, it is important to note that the small NEFA pool constituting 2-3\% of the total fatty acid pool, generally serves as the major extracellular source of fatty acid for cultured cells (Spector et al., 1981). As can be seen in the NEFA fraction of the conditioned media, the 18:0, 18:1n-9, 18:2n-6 and 20:5n-3 contents have changed drastically due to the additions (Table 1). The results of the analysis of cardiomyocyte phospholipids under the influence of these various fatty acid supplements are shown in Table 2.

There was no detectable change due to fatty acid treatment of the cardiomyocytes in the relative or absolute amounts of phosphatidylcholine (PC), phosphatidylethanolamine (PE), phosphatidylinositol (PI) and sphingomyelin (SPM) fractions separated by one-dimensional thin-layer-chromatography (TLC). The composition is similar to that reported by Post et al. (1988) for cultures of neonatal 
TABLE 2 Class composition of total phospolipids from control cardiomyocytes and cells treated with $18: 0 / 18: 1 n-\mathrm{g}, 18: 2 n-6$ or $20: 5 n-3$

\begin{tabular}{lccrr}
\hline $\begin{array}{l}\text { Class of } \\
\text { phospholipid }\end{array}$ & $\begin{array}{c}\text { Control } \\
n=6^{\mathrm{a}}\end{array}$ & $\begin{array}{c}18: 0 / 18: 1 n-\mathrm{g} \\
n=2\end{array}$ & $\begin{array}{c}18: 2 n-6 \\
n=5\end{array}$ & $\begin{array}{c}20: 5 n-3 \\
\text { mol percentage }(S . E .)\end{array}$ \\
\hline PC & & 48.8 & $44.4(4.4)$ & $52.0(5.1)$ \\
PE & $45.9(5.0)$ & 30.0 & $31.8(4.8)$ & $27.2(3.6)$ \\
PS & $30.9(3.3)$ & 4.4 & $5.3(1.4)$ & $4.9(1.1)$ \\
PI & $4.0(0.6)$ & 9.1 & $9.4(1.0)$ & $8.5(0.8)$ \\
SPM & $9.0(1.2)$ & 7.7 & $9.1(1.2)$ & $7.2(1.7)$ \\
\hline
\end{tabular}

The composition is calculated from gaschromatographic analysis of the prepared methylesters of the fatty acids constituting the respective phospholipid classes. No differences were found between the respective absolute phospholipid fatty acid contents (respectively $191 \pm 10,178,178 \pm 9$ and $202 \mathrm{nmol} / \mathrm{mg}$ protein) of control-, 18:0/18:1n-9-, 18:2n-6- and 20:5n-3 treated cardiomyocytes. Values are presented as means (S.E.).

${ }^{a}$ Number of determinations of the phopholipid class contents in each group of control or fatty acid treated cells.

cardiomyocytes except that in the present study PI and PS were determined separately. Since the amounts of the phospholipid classes were found to be the same in all four cell treatments, it was decided to express the results of fatty acid composition in mol\%. The results of the fatty acid analysis of the major phospholipid fractions PC and PE are shown in Table 3.

Supplementation of the culture medium with 18:0/18:1n-9 mixture caused a marked increase in incorporation of these fatty acids in PC and predominantly a reduction in 16:0, $18: 1 n-7$ and $20: 4 n-6$ and the sum of PUFA decreased from 33.9 to $24.7 \mathrm{~mol} \%$. However, the $n-3 / n-6$ PUFA molar ratio decreased from 0.17 to 0.11 resulting from a slight shift in incorporation of $n-6$ PUFA in favor of $n-3$ PUFA. Treatment of the cells with 18:2n-6 caused a dramatic increase of $18: 2 n-6$ to 42.1 mol\% of the total PC fatty acids and a decrease of incorporated 18:2n-6 metabolites, 20:4n-6 and 22:4n-6 (Table 3). There was still a marked increase of $\Sigma$ PUFA from 33.9 to $49.9 \mathrm{~mol} \%$. The massive incorporation of 18:2n-6 into the fatty acids of PC, depressed the $n-3 / n-6$ PUFA molar ratio to almost zero. Treatment of the cardiac cells with 20:5n-3 led to increased incorporation of this fatty acid and also of 22:5n-3 in PC. The increased incorporation of $n-3$ PUFA occurred at the expense of $n-6$ PUFA as the sum of $18: 2 n-6$ and $20: 4 n-6$ decreased from 26.5 to 12.6 mol\%. Although EPUFA increased significantly from 33.9 to $41.5 \mathrm{~mol} \%$ after $20: 5 n-3$ treatment, the increase was much less compared to $18: 2 n-6$ treatment. Thus it appeared that cardiomyocyte $\mathrm{PC}$ more readily incorporated 18:2n-6 than 20:5n-3.

The general patterns of changes in phospholipids PE, PI and PS following fatty acid treatment of the cells were very similar to those seen in PC (Tables 3 and 4). There are, however, some interesting differences between the fatty acid composition of the various phospholipid classes per se and some phospholipid class-specific responses to fatty acid treatment. The preferential incorporation of 18:2n-6 compared with $20: 4 n-6,20: 5 n-3$ and $22: 5 n-3$ was observed predominantly with $P C$, as the highest 18:2n-6 incorporation among the other phospholipid classes was certainly less than $22 \mathrm{~mol} \%$. This difference between PC and the other phospholipid classes PE, PI and PS can not be explained by the low PUFA contents of the non-PC phospholipid classes; on the contrary, the LPUFA of e.g. PE of control treated cells reaches almost $50 \mathrm{~mol} \%$ (Table 3).

The results in Tables 3 and 4 show that PE, PI and even PS in control treated cells contain much more $20: 4 n-6$ relative to $18: 2 n-6$ (e.g. PI contains 30.0 relative to $4.4 \mathrm{~mol} \%$ ). Another remarkable finding is the relative homogeneity in fatty acid composition of the PI fraction in control treated cardiomyocytes. The PI fraction is mainly composed of molecular species with 18:0 on the $s n-1$ site and $20: 4 n-6$ on the $s n-2$ site of the glycerol moiety. This homogeneity disappeared when the cardiomyocytes are exposed to the various types of fatty acid. It should also be noticed that in the PS fraction, in contrast to the other major phospholipid classes, there is a preferential incorporation of the 20:5n-3 metabolite $22: 5 n-3$. 


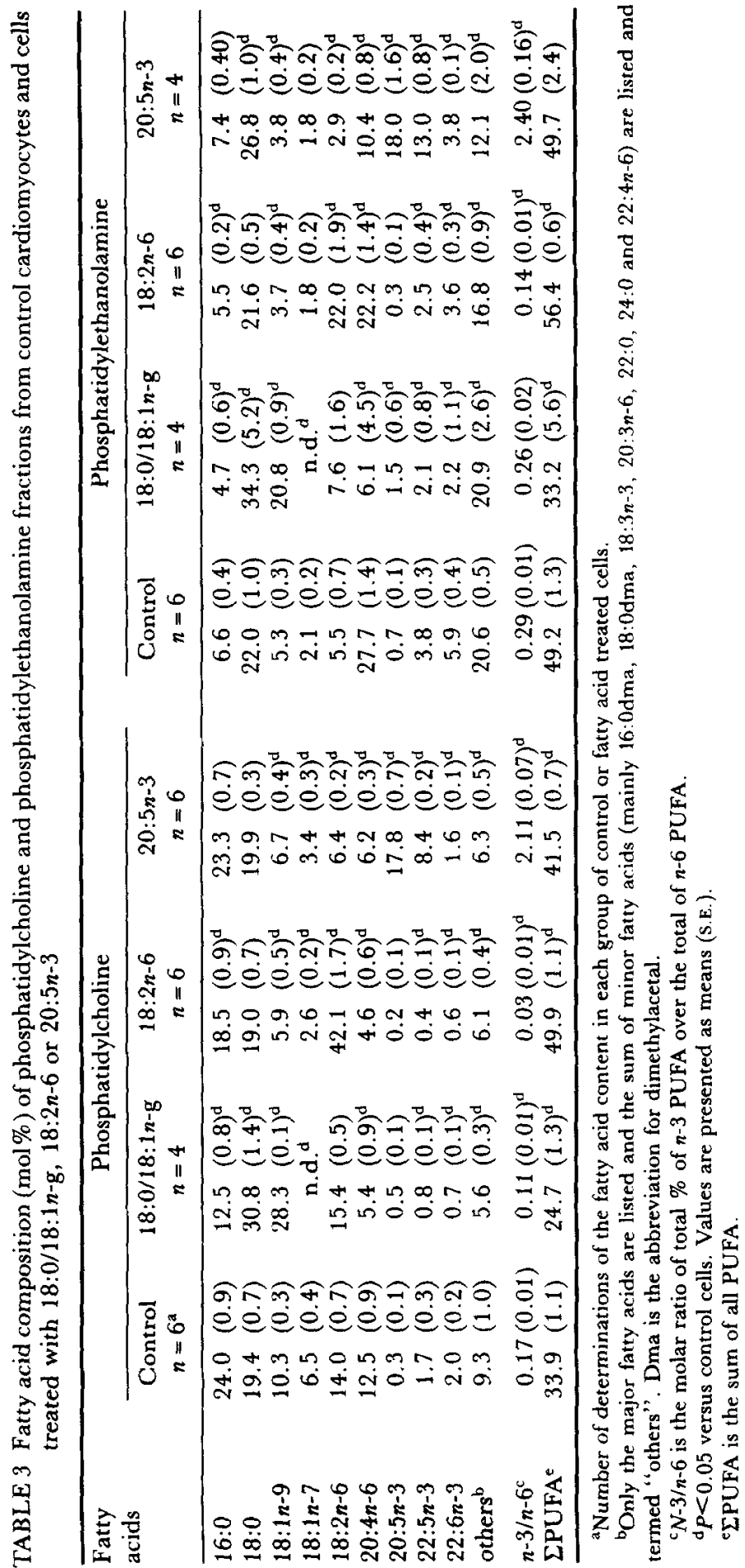




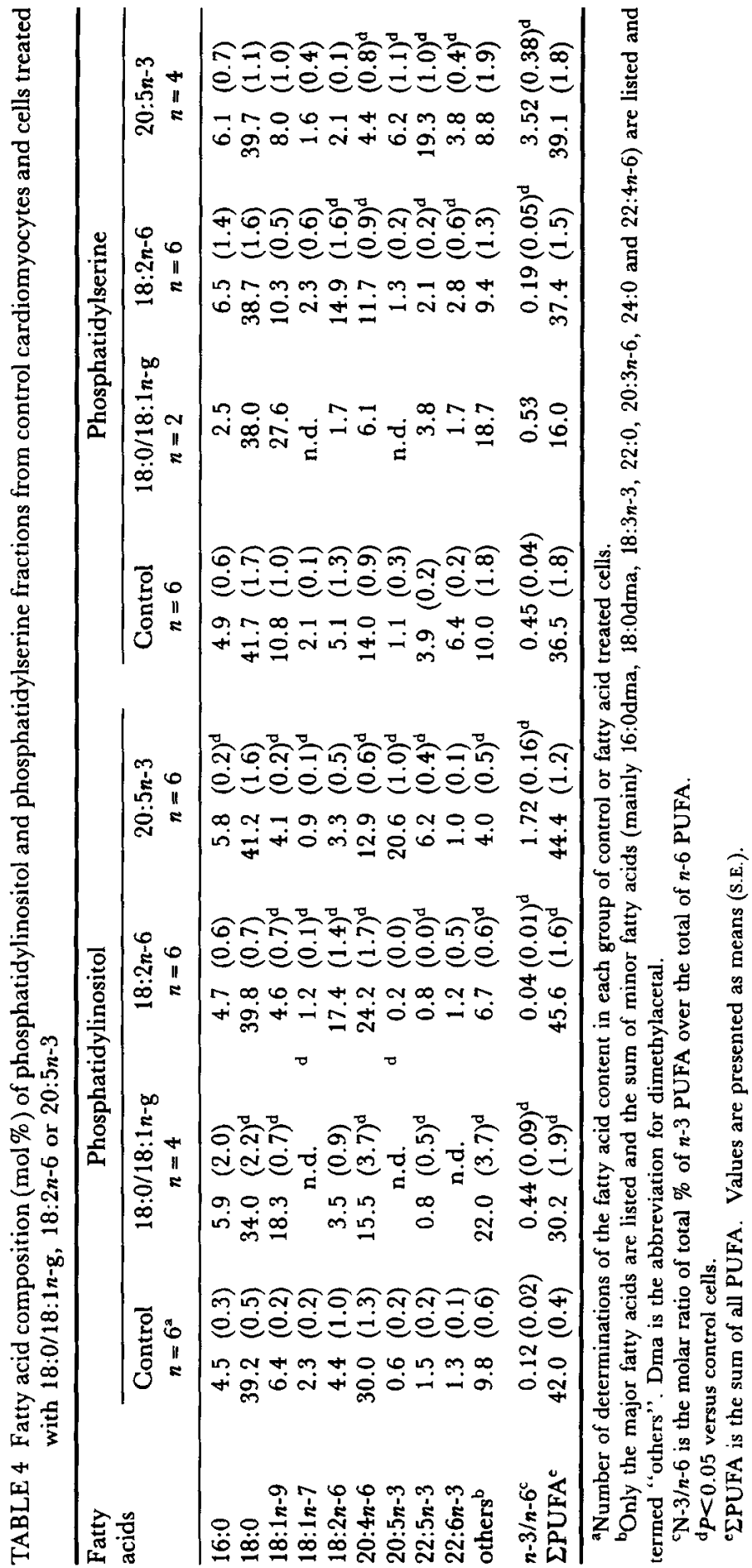


TABLE 5 Fatty acid composition ( $\mathrm{mol} \%$ ) of the sphingomyelin fraction from control cardiomyocytes and cells treated with $18: 0 / 18: 1 n-\mathrm{g}, 18: 2 n-6$ or $20: 5 n-3$

\begin{tabular}{lrcrr}
\hline $\begin{array}{l}\text { Fatty } \\
\text { acids }\end{array}$ & $\begin{array}{c}\text { Control } \\
n=4^{\mathrm{a}}\end{array}$ & $\begin{array}{c}18: 0 / 18: 1 n-\mathrm{g} \\
n=2\end{array}$ & $\begin{array}{c}18: 2 n-6 \\
n=4\end{array}$ & $\begin{array}{c}20: 5 n-3 \\
n=3\end{array}$ \\
\hline $16: 0$ & $26.6(1.3)$ & 22.1 & $28.5(2.2)$ & $36.3(2.2)^{\mathrm{d}}$ \\
$18: 0$ & $19.1(1.5)$ & 28.5 & $17.4(1.7)$ & $15.5(3.3)$ \\
$18: 1 n-9$ & $4.0(0.5)$ & 5.6 & $4.2(0.9)$ & $4.4(1.0)$ \\
$18: 2 n-6$ & $2.7(0.9)$ & 0.6 & $3.9(1.3)$ & $1.0(0.0)$ \\
$20: 0$ & $9.2(0.6)$ & 8.5 & $8.8(0.6)$ & $6.6(0.1)$ \\
$22: 0$ & $9.1(0.7)$ & 10.1 & $8.4(1.2)$ & $7.8(1.0)$ \\
$20: 4 n-6$ & $3.8(0.8)$ & 2.3 & $4.7(1.2)$ & $3.3(0.2)$ \\
$24: 0$ & $10.5(1.0)$ & 11.1 & $7.6(0.5)$ & $8.2(1.0)$ \\
$20: 5 n-3$ & $0.8(0.4)$ & $n . d$. & $0.3(0.0)$ & $1.1(0.1)$ \\
$24: 1 n-9$ & $8.5(0.7)$ & 8.9 & $8.5(0.8)$ & $9.0(1.0)$ \\
others & $5.8(0.9)$ & 2.8 & $7.6(2.4)$ & $6.8(1.5)$ \\
$n-3 / n-6^{c}$ & $0.40(0.11)$ & 0.28 & $0.32(0.13)$ & $0.61(0.05)$ \\
EPUFA & $9.6(1.9)$ & 3.6 & $11.8(2.7)$ & $7.6(1.3)$ \\
\hline
\end{tabular}

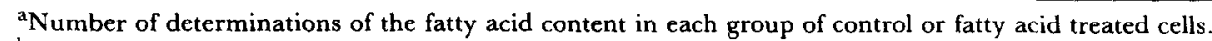

${ }^{b}$ Only the major fatty acids are listed and the sum of minor fatty acids (mainly 16:0dma, 18:0dma, 18:1n-7, 18:3n-3) are listed and termed "others". Dma is the abbreviation for dimethylacetal.

${ }^{\mathrm{c}} N-3 / n-6$ is the molar ratio of total \% of $n-3$ PUFA over the total of $n-6$ PUFA.

d $P<0.05$ versus control cells.

'SPUFA is the sum of all PUFA. Values are presented as means (S.E.).

SPM is a choline-containing phospholipid with only one fatty acid esterified per molecule. Long-chain (mono) unsaturates are reported to be mainly present. The results abtained from the cardiomyocyte are summarized in Table 5 and confirm this distinct SPM property as the 16:0, 18:0, 20:0, $22: 0,24: 0$ and $24: 1 n-9$ contents vary between 8 and $27 \mathrm{~mol} \%$ whereas the contents of 18:2n-6 and 20:5n-3 were both lower than $4 \mathrm{~mol} \%$. Therefore it is not suprisingly that $18: 2 n-6$ or $20: 5 n-3$ treatment of the cells did not lead to incorporation of these fatty acids into SPM. In contrast, slight changes in the $24: 0$ content of SPM in response to $18: 2 n-6$ treatment and in the 16:0 and 20:0 content in response to $20: 5 n-3$ treatment had occurred.

\section{The rate of $\mathrm{PIP}_{2}$ hydrolysis}

The cardiomyocytes, pretreated with control medium and 18:0/18:1n-9, 18:2n-6 or $20: 5 n-3$ rich medium, were tested for the basal and $\alpha_{1}$-adrenoceptor stimulated rate of $\mathrm{PIP}_{2}$ hydrolysis. The $\left[{ }^{3} \mathrm{H}\right]-\mathrm{IP}_{\mathrm{n}}$ production (Fig. 1) represents the sum of $\left[{ }^{3} \mathrm{H}\right]-\mathrm{IP},\left[{ }^{3} \mathrm{H}\right]-\mathrm{IP}_{2}$ and $\left[{ }^{3} \mathrm{H}\right]-\mathrm{IP}_{3}$ formation. Previously we have shown that the major $\mathrm{IP}_{\mathrm{n}}$ formed is the mono- phosphate, due to the rapid breakdown of $\mathrm{IP}_{2}$ and $\mathrm{IP}_{3}$ by phosphatases during cell incubation. The $\mathrm{IP}_{\mathrm{n}}$ formation was measured over a period of $30 \mathrm{~min}$. Cardiomyocyte exposure to 18:0/18:1n-9 stimulates basal $\mathrm{PIP}_{2}$ hydrolysis $37 \%$ whereas partial inhibition was found after exposure to $18: 2 n-6$ and 20:5n-3 (35 and $49 \%$, respectively). The maximal rate of $\mathrm{PIP}_{2}$ hydrolysis that can be reached by adding $30 \mu \mathrm{M}$ phenylephrine was not significantly affected by 18:0/18:1 $n$-g treatment but was also partially inhibited by treatment with the $n-6$ and $n-3$ PUFA $(51 \%$ and $71 \%$, respectively).

No selective depletion of any specific type of PUFA occurred in the PI fraction of the cardiomyocytes stimulated for $30 \mathrm{~min}$ with a maximal dosis of phenylephrine [Fig. 2(a) and (b)]. Similarly, the analysis of non-PI phospholipids showed no changes in fatty acid patterns due to $\alpha_{1}$-adrenergic stimulation (results not shown).

\section{$\left[{ }^{3} H\right]$-Inositol incorporation in membrane (polyphospho)PI lipids}

The $\left[{ }^{3} \mathrm{H}\right]$-inositol incorporation into the membrane (polyphospho)PI lipids was measured during the final $24 \mathrm{~h}$ of the three 


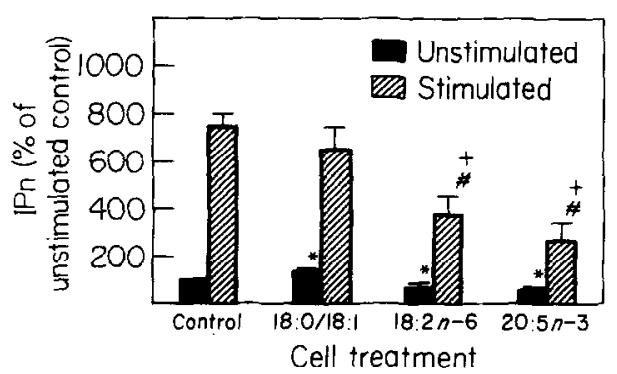

FIGURE 1. The basal rate and $\alpha_{1}$-adrenoceptor mediated phosphatidylinositol-4,5-bisphosphate breakdown of control cardiomyocytes and cells treated with 18:0/18:1n-9, 18:2n-6 or 20:5n-3. The incubation time was $30 \mathrm{~min}$ and the phenylephrine concentration for stimulation of the PI cycle was $30 \mu \mathrm{M}$. The columns are means, bars are S.E., of $\left[{ }^{3} \mathrm{H}\right]-\mathrm{IP}_{\mathrm{n}}$ formation expressed as $\%$ of the unstimulated control value in 7 experiments. ${ }^{*} P<0.05$ us unstimulated control treated cells; ${ }^{\#} P<0.05$ vs stimulated control treated cells; ${ }^{+} P<0.05$ vs stimulated 18:0/18:1n-9 treated cells.
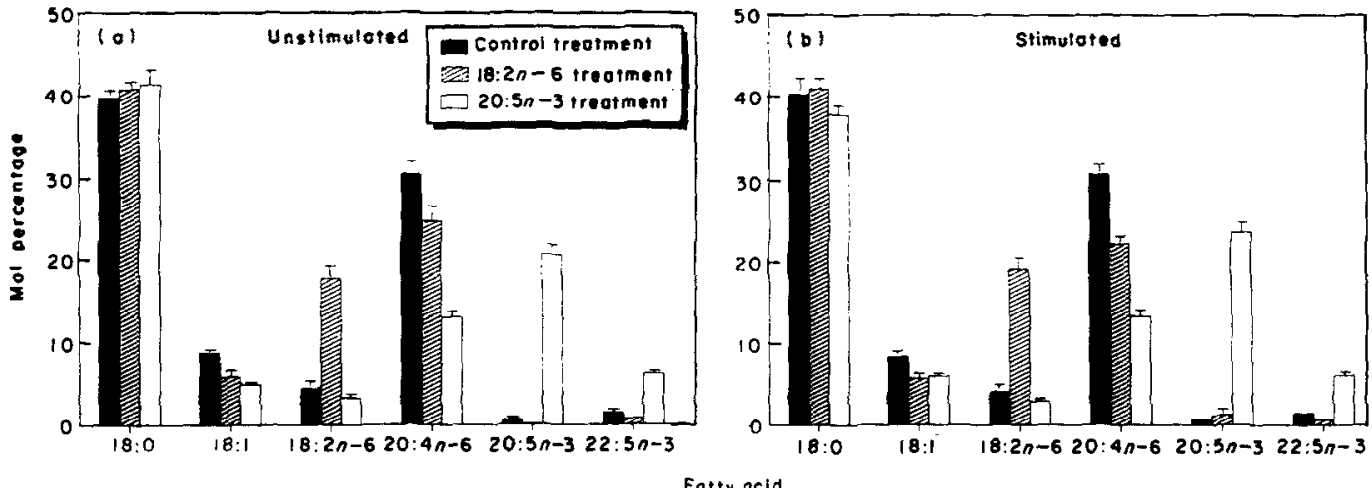

FIGURE 2. The effect of no stimulation (a) or prolonged stimulation of PI cycle (b) on the fatty acid composition of the PI fraction from control cardiomyocytes and cells treated with 18:0/18:1n-9, 18:2n-6 or 20:5n-3. The incubation time was $30 \mathrm{~min}$ and the phenylephrine concentration for the stimulation was $30 \mu \mathrm{M}$. After incubating of the cells the phospholipids were extracted and PI separated by TLC. Only the major fatty acids are shown. The columns are means, bars are S.E. of mol\% of the specific fatty acid of PI in 5 experiments.
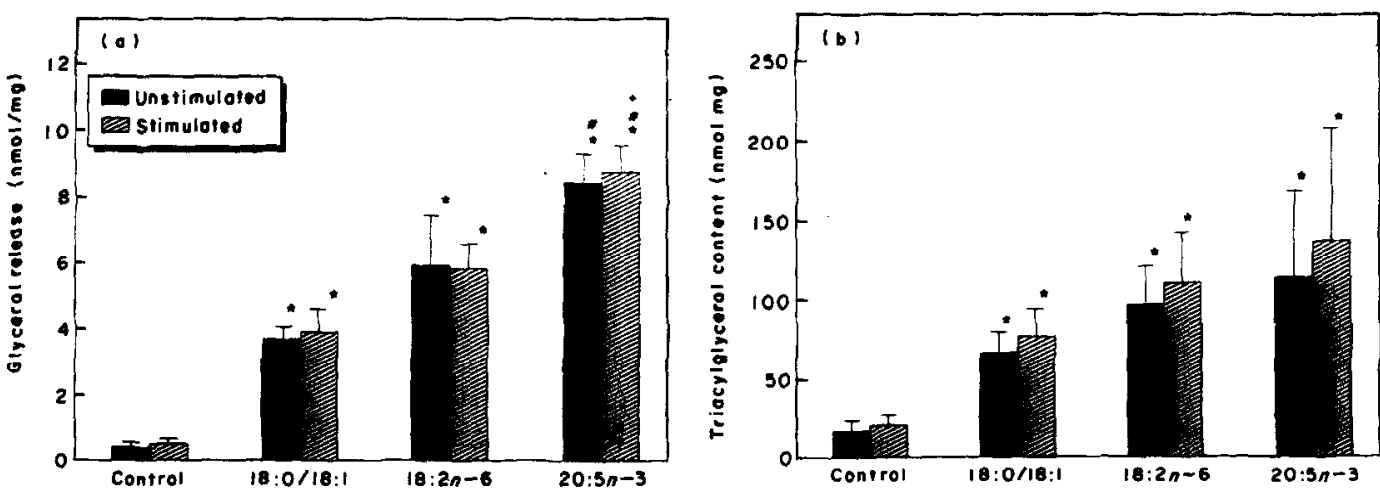

FIGURE 3. The rate of lipolysis (a) and the triacylglyceride content (b) of unstimulated and phenylephrine-stimulated cardiomyocytes, control cells and cells treated with 18:0/18:1n-9, 18:2n-6 or 20:5n-3. Glycerol release as a measure of lipolysis was determined over an incubation period of $30 \mathrm{~min}$. The phenylephrine concentration for the stimulation of the PI cycle is $30 \mu \mathrm{M}$. The columns are mcans, bars are S.E., of glycerol release and TG contents in respectively 4 and 5 experiments.

${ }^{*} P<0.05$ vs control treated cells; $P<0.05$ us corresponding values of 18:0/18:1n-9 treated cells; ${ }^{+} P<0.05$ vs corresponding value of $18: 2 n-6$ treated cells. 
TABLE $6\left[{ }^{3} \mathrm{H}\right]$-inositol incorporation into (polyphospho)PI lipids of control cardiomyocytes and cells treated with $18: 0 / 18: 1 n-g, 18: 2 n-6$ and $20: 5 n-3$

\begin{tabular}{|c|c|c|c|c|c|c|c|c|}
\hline \multirow[b]{2}{*}{$\begin{array}{l}\text { PI, dpmin } \\
\text { PI, \%क }\end{array}$} & \multicolumn{2}{|c|}{ Control } & \multicolumn{2}{|c|}{$18: 0 / 18: 1 n-g$} & \multicolumn{2}{|c|}{$18: 2 n-6$} & \multicolumn{2}{|c|}{$20: 5 n-3$} \\
\hline & $\begin{array}{c}39346 \\
93.2\end{array}$ & $\begin{array}{l}(509) \\
(0.2)\end{array}$ & $\begin{array}{r}38467 \\
93.9\end{array}$ & $\begin{array}{l}(831) \\
(0.4)\end{array}$ & $\begin{array}{c}35022 \\
92.8\end{array}$ & $\begin{array}{l}(579)^{\mathrm{a}} \\
(0.3)\end{array}$ & $\begin{array}{c}31112 \\
93.4\end{array}$ & $\begin{array}{l}(409)^{\mathrm{a}} \\
(0.3)\end{array}$ \\
\hline $\begin{array}{l}\text { PIP, dpm } \\
\text { PIP, \% }\end{array}$ & $\begin{array}{l}1381 \\
3.24\end{array}$ & $\begin{array}{l}(70) \\
(0.19)\end{array}$ & $\begin{array}{c}1263 \\
3.27\end{array}$ & $\begin{array}{l}(64) \\
(0.16)\end{array}$ & $\begin{array}{l}1369 \\
3.71\end{array}$ & $\begin{array}{l}(94) \\
(0.20)\end{array}$ & $\begin{array}{l}1078 \\
3.22\end{array}$ & $\begin{array}{l}(53)^{2} \\
(0.16)\end{array}$ \\
\hline $\begin{array}{l}\mathrm{PIP}_{2}, \text { dpm } \\
\operatorname{PIP}_{2}, \%\end{array}$ & $\begin{array}{l}1545 \\
3.58\end{array}$ & $\begin{array}{l}(50) \\
(0.13)\end{array}$ & $\begin{array}{l}1407 \\
3.38\end{array}$ & $\begin{array}{l}(57) \\
(0.10)\end{array}$ & $\begin{array}{l}1351 \\
3.64\end{array}$ & $\begin{array}{l}(66)^{\mathrm{a}} \\
(0.12)\end{array}$ & $\begin{array}{l}1166 \\
3.32\end{array}$ & $\begin{array}{l}(36)^{\mathrm{a}} \\
(0.10)\end{array}$ \\
\hline $\begin{array}{l}\text { Sum, dpm } \\
\text { Sum, \% }\end{array}$ & $\begin{array}{l}42062 \\
100\end{array}$ & $(381)$ & $\begin{array}{l}41439 \\
100\end{array}$ & $(896)$ & $\begin{array}{l}37387 \\
100\end{array}$ & $(508)^{a}$ & $\begin{array}{l}33273 \\
100\end{array}$ & $(372)^{\mathrm{a}}$ \\
\hline
\end{tabular}

During the final $24 \mathrm{~h}$ of control or fatty acid treatment of the cardiomyocytes $88 \mathrm{nM}\left[2-{ }^{3} \mathrm{H}\right]-$ myoinositol $\left(2 \mu \mathrm{C}_{\mathrm{i}} / \mathrm{ml}\right)$ was added. At the end of the preincubation of the cardiomyoctyes with the conditioned media the (polyphospho)PI lipids were extracted, separated on TLC and counted by liquid scintillation. Sum means total (polyphospho)PI lipids $\left(\mathrm{PI}+\mathrm{PIP}+\mathrm{PIP}_{2}\right)$. Incorporation is expressed as ${ }^{b} \mathrm{dpm} / 4$-well multidish and as ${ }^{c} \%$ of the total (polyphospho)PI lipid fraction. Values are presented as means (S.E.) of 16 experiments ${ }^{a} P<0.05$ vs control cells.

days lasting incubation of cardiomyocytes with control or fatty acid supplemented medium has also been measured (Table 6). The relative distribution of $\left[{ }^{3} \mathrm{H}\right]$-inositol into PI, PIP and PIP $_{2}$ remained unaffected by the fatty acid treatments. It should be noticed that $\mathrm{PIP}_{2}$ constitutes only about $3.5 \%$ of the total (polyphospho)PI lipid fraction. The absolute $\left[{ }^{3} \mathrm{H}\right]$-inositol incorporation in PI, PIP and $\mathrm{PIP}_{2}$ was $30 \%$ reduced by $20: 5 n-3$, but only $10 \%$ by $18: 2 n-6$ treatment of the cardiomyocytes. No effect was observed when the cardiomyocytes were treated with 18:0/18:1n-g.

\section{Cellular TG content and the rate of lipolysis}

In order to explore the effect of fatty acid treatment of cardiomyocytes on neutral lipid metabolism, the cellular $\mathrm{TG}$ contents and rates of lipolysis were measured [Fig. 3(B)]. A large increase of cellular TG content and rate of lipolysis was seen after fatty acid treatment. The increases were not much dependent of the type of fatty acid treatment, although the glycerol release in $20: 5 n-3$ treated cells was significantly higher than that in 18:0/18:1n-9 treated cells. Stimulation of the cells by phenylephrine $(30 \mu \mathrm{M})$ did not affect the rate of lipolysis.

\section{Discussion}

Fatty acid composition of membrane phospholipids

To delineate the mechanism(s) of the reported reduction of the $\alpha_{1}$-adrenergic inotropic response by dietary $n-3$ vs. $n-6$ PUFA in the Langendorff perfused rat heart (Reibel et al., 1988), we studied rat neonatal cardiomyocytes cultured in fatty acid enriched media. This preparation has severai advantages: (i) it allows the examination of the $\alpha_{1}$-adrenoceptor mediated PI response in the cardiomyocyte free from other cell types in the myocardium (e.g. vascular smooth muscle and endothelial cells) known to possess an active PI turnover; (ii) cardiomyocytes survive in culture medium for several days allowing incorporation in vitro of specific fatty acids into cell membrane phospholipids and (iii) the myocyte polyphosphoinositide pool is more accessible for radioactive labelling with $\left[{ }^{3} \mathrm{H}\right]$-myoinositol than in whole heart preparations.

As a consequence of supplementation of the culture medium with fatty acids the cardiomyocyte phospholipid composition varied widely, whereas its phospholipid class contents and composition were unchanged. In our experiments the total NEFA pool in the media varied between $30 \mu \mathrm{M}$ (control treated cells) and $240 \mu \mathrm{M}$ (fatty acid treated cells), concentrations which are less than twice the albumin concentration in the added sera. The albumin prevents fatty acid toxicity based on our previous observations that cardiac sarcolemmal membrane integrity is affected when NEFA to albumin molar ratio exceeds 5 (Lamers et al., 1984). Furthermore, intracellular accumulation of NEFA was prevented by incorporation into TG. Indeed, the present study shows fatty acid treatment induced 
accumulation of TG in the cardiomyocytes and this effect has been reported for other cultured cell preparations (Spector et al., 1981). The rate of TG synthesis is primarily determined by the availability of initial substrates glycerol-3-phosphate and acylCoA, which are derived from stored glycogen (or extracellular glucose) and NEFA (Stam et al., 1987), respectively. The TG accumulation likely was harmless as the cells continue to beat spontaneously at a constant rate (data not shown), although possible changes in the amplitude of contraction had not been measured. Hasin et al. (1982) cultured neonatal rat heart cells for up to 16 days in medium containing $20 \%$ animal sera supplemented with $50 \mu \mathrm{M} 18: 0$ or $18: 2 n-6$ with no apparent loss of viability.

The predicted elevations of $18: 1 n-9,18: 2 n-6$ and 20:5n-3 associated with a partial depletion of 20:4n-6 were confirmed in all phospholipid classes except for SPM, of the respective groups of fatty acid treated cells. In the $20: 5 n-3$ treatment group, the change in $n-3 / n-6$ PUFA molar ratio of e.g. the major phospholipid class $\mathrm{PC}$ from 0.17 to 2.11 was even more pronounced than that reported by Reibel et al. (1988) for the total phospholipid fraction (from 0.31 to 1.14 ) after feeding rats with fish oil. In spite of the similar patterns of changes, each phospholipid class had an unique fatty acid composition and a distinct response to the fatty acid treatments. In particular, the PI fraction, which was very homogeneous in fatty acid composition in control treated cells, changed dramatically after the fatty acid treatments. The results of the control treated cells showed that $20: 4 n-6$ is enriched $(30.0 \%)$ in the PI fraction and that the other major fatty acid appeared to be 18:0 $(39.2 \mathrm{~mol} \%)$. These findings are in agreement with the generally accepted, but not experimentally proven, proposal in the literature that the $s n-2$ position of $\mathrm{PIP}_{2}$ mainly is occupied by $20: 4 n-6$, which is released in the form of $\mathrm{DG}$ after receptor-mediated stimulation of $\mathrm{PIP}_{2}$ hydrolysis (Berridge, 1984). This homogeneity in the PI fraction was no longer apparent when the cells were treated with $18: 0 / 18: 1 n-9,18: 2 n-6$ or $20: 5 n-3$. In the 18:0/18:1n-9 treated cells $18: 1 n-9$ was incorporated into PI to a large extent (from 6.5 to $18.3 \mathrm{~mol} \%$ ) in contrast to the $18: 0$ content of PI which actually decreased (from 39.2 to $34.0 \mathrm{~mol} \%$ ). In the $18: 2 n-6$ treated cells $18: 2 n-6$ is incorporated into PI to a large extent (from 4.4 to $17.4 \mathrm{~mol} \%$ ) and even more avidly into PC (from 14.0 to $42.1 \mathrm{~mol} \%$ ). In the 20:5n-3 treated cells, both $20: 4 n-6$ and 20:5n-3 were enriched in the PI fraction (12.9 and $20.6 \%$, respectively). In general it can be concluded that the main effect of all three fatty acid treatments on the various phospholipid classes was a partial replacement of the $20: 4 n-6$.

No desaturation of $18: 2 n-6$ occurred which finding is in agreement with the results reported by Hagve and Sprecher (1989). We were also able to show that neonatal rat heart myocytes have the capacity to elongate C20 fatty acids. This was not observed by Hagve and Sprecher (1989), who studied the metabolism of labelled 20:5n-3 in cardiomyocytes isolated, but not cultured, from the adult rat heart.

\section{Rates of basal and $\alpha_{1}$-adrenoceptor mediated $P I P_{2}$ hydrolysis}

The rate of basal and $\alpha_{1}$-adrenoceptor mediated PI turnover was largely affected by the changes in fatty acid composition of PI and/or all other phospholipid classes. Apart from the observed reductions in the basal rates, the phenylephrine $(30 \mu \mathrm{M})$ stimulated production of inositolphosphates was reduced by $51 \%$ and $71 \%$, respectively in the $18: 2 n-6$ and $20: 5 n-3$ treated cardiomyocytes. The basal rate of inositolphosphate formation was $37 \%$ increased in the 18:0/18:1n-9 treated cells. Under the present experimental conditions, the NEFA added to the culture medium were washed away prior to the activation of $\mathrm{PIP}_{2}$ breakdown. Therefore it is unlikely, that a direct activation of protein kinase $\mathrm{C}$ by extracellularly derived PUFA is involved in the observed decrease in the rate of $\mathrm{PIP}_{2}$ breakdown induced by $n-6$ or $n-3$ PUFA treatment of the cardiomyocytes (McPhail et al., 1984 and Meij and Lamers, 1989b). Thus the effects on the PI cycle in this study can be attributed to the different composition of the membrane lipids. Since the changes of the various phospholipid classes induced by the fatty acid treatment were complex, it is not possible to identify one of them, e.g. a change 
of $n-3 / n-6$ PUFA molar ratio, 2 PUFA, or $20: 4 n-6$ content of PI, to be causally related to the changes in basal and/or $\alpha_{1}$-adrenoceptor mediated rate of $\mathrm{PIP}_{2}$ breakdown. Therefore no firm conclusions can be drawn from the results of the present study to explain the possible mechanism(s) of changes in the rate of $\mathrm{PIP}_{2}$ breakdown. One possible mechanism would be that the fatty acids induce changes in the membrane content of $\mathrm{PIP}_{2}$. For this reason we measured the $\left[{ }^{3} \mathrm{H}\right]$-inositol incorporation during the final $24 \mathrm{~h}$ of the three days lasting incubation of cardiomyocytes with control or fatty acid supplemented medium. The relative distribution of $\left[{ }^{3} \mathrm{H}\right]$-inositol into PI, PIP and PIP $_{2}$ remained unaffected by the fatty acid treatments. The latter indicates that the equilibrium concentrations of these lipids are well maintained by active PI- and PIP-kinases and active PIP and $\mathrm{PIP}_{2}$-phosphatases. The absolute $\left[{ }^{3} \mathrm{H}\right]$-inositol incorporation in PI, PIP and $\mathrm{PIP}_{2}$ was $28 \%$ reduced by $20: 5 n-3$, but only $12 \%$ by $18: 2 n-6$ treatment of the cardiomyocytes. Therefore, a partial contribution of PUFA-induced reduction of the $\mathrm{PIP}_{2}$ level to the attenuation of basal and $\alpha_{1}$-adrenoceptor mediated $I P_{n}$ production can not be excluded. At present it is not clear how PUFA cause a reduction of $\left[{ }^{3} \mathrm{H}\right]$-inositol incorporation into the (polyphospho)PI lipids. They may interact with several enzymatic steps in the regeneration of PI from $\mathrm{IP}_{3}$ and DG or with the transport of inositol across the plasma membrane.

Reibel et al. (1988) demonstrated that dietary $n$ - 3 PUFA result in a reduction of the $\alpha_{1}$-adrenergic inotropic response. The present data on $20: 5 n-3$ treatment of cultured cardiomyocytes offer a possible mechanism of action of dietary $n-3$ PUFA via the $\mathrm{IP}_{3}$ pathway and unlikely involving the eicosanoid pathway. Indeed, Reibel et al. (1988) showed already that changes in eicosanoid production were unrelated to the effects of dietary fish oil on $\alpha_{1}$-adrenergic stimulation. The reduced $\alpha_{1}$-adrenergic response caused by dietary $n-3$ PUFA could protect the myocardium against the pathophysiological consequences of cate- cholamine release evoked by chronic adrenergic or ischemic stress (Gudbjarnason et al., 1978 and Hartog et al., 1987).

\section{Fatty acid composition of $P I$ after prolonged $\alpha_{1}$-adrenergic stimulation}

Previously we demonstrated that maximal stimulation by phenylephrine over a prolonged period $(30 \mathrm{~min})$ did not reduce the PI, PIP and PIP $_{2}$ contents of the cardiomyocyte membranes (Meij and Lamers, 1989b). This means that the cells have the capacity to rapidly resynthesize PI from CDP-diacylglyceride and inositol and subsequently to polyphosphorylate PI. A change in the PI fatty acid composition after prolonged stimulation of the PI cycle would be likely to occur, because the resynthesized PI will obtain its precursor fatty acids from a mixed pool of diacylglycerides (DG). In the present study no significant depletion of any of the PUFA occurred in the $\alpha_{1}$-adrenergic stimulated cardiomyocytes, not even in the PI fraction. We (Montfoort et al., 1986) and others (Gudbjarnason et al., 1978) have shown that chronic noradrenaline stress in rats resulted in an increase in $n-3 / n-6$ PUFA molar ratio of the total phospholipid fraction. Based on the present results this stress effect may be purely of $\beta$-adrenergic nature. However, the latter hypothesis should be tested using a $\beta$ adrenergic agonist in the incubation of the cultured cardiomyocytes.

In conclusion, variations in the PUFA composition of membrane phospholipids do affect the basal and the $\alpha_{1}$-adrenoceptor stimulated rate of $\mathrm{PIP}_{2}$ hydrolysis. The reducing effects of $18: 2 n-6$ and $20: 5 n-3$ treatment may be partially ascribed to lowering of PIP $_{2}$ levels.

\section{Acknowledgements}

This work was supported by a grant from the Netherlands Organization of Scientific Research (NWO) and the NATO, Belgium.

\section{References}

BERRIDGe MJ, DOWNes CP, HANley MR (1982) Lithium amplifies agonist-dependent phosphatidylinositol responses in brain and salivary glands. Biochem $\mathrm{J}$ 206: 587-595. 
BERRIDGE MJ (1984) Review article: inositoltrisphosphate and diacylglycerol as second messengers. Biochem J 220 345-360.

BLIGH EG, DYER WJ (1959) A rapid method of total lipid extraction and purification. Can J Biochem Physiol 37: 911-918.

Blondel B, Roijen I, Cheneval JP (1971) Heart cells in culture: A simple method for increasing the proportion of myoblasts. Experientia 27: 356-358.

Gilfillan AM, ChU AJ, SMART DA, ROONEY SA (1983) Single plate separation of lung phospholipids including disaturated phosphatidylcholine. J Lipid Res 24: 1651-1656.

Grynberg A, Fantini E, Athias P, Degois M, Guenot L, Courtois L, Khatami S (1988) Modification of the $n-6 / n-3$ fatty acid ratio in the phospholipids of rat ventricular myocytes in culture by the use of synthetic media: Functional and biochemical consequences in normoxic and hypoxic conditions. J Mol Cell Cardiol 20: 863-874.

Gudbjarnason S, OskardottiR G, Doell B, Hallgrimson J (1978) Myocardial membrane lipids in relation to cardiovascular disease. Adv Cardiol 25: 130-144.

HaGVe TA, Sprecher H (1989) Metabolism of long-chain polyunsaturated fatty acids in isolated cardiomyocytes. Biochim Biophys Acta 1001: 338-344.

Hallae H, Sellmayer A, Smith TW, Leaf A (1990) Protective effect of eicosapentaenoic acid on ouabain toxicity in neonatal rat cardiac myocytes. Proc Natl Acad Sci 87: 7834-7838.

Hartog JM, Lamers JMJ, Achterberg PW, van Neuven-Nolsen D, Nijkamp FP, Verdouw PD (1987) The effects of dietary mackerel oil on the recovery of cardiac function after acute ischaemic events in the pig. Basic Res Cardiol 82 (Suppl. 1): 223-234.

Hasin Y, Sapoznikov D, Stein O, STEIN Y (1982) Effect of fatty acid composition of rat heart myocytes on their electrical activity. J Mol Cell Cardiol 14: 163-171.

Laurell S, Tibbling G (1966) An enzymatic micromethod for the determination of glycerol. Clin Chim Acta 13: 317-322.

Lamers JMJ, Stinis HT, Montfoort A, Hülsmann WC (1984) The effect of lipid intermediates on $\mathrm{Ca}^{2+}$ and $\mathrm{Na}^{+}$ permeability and $\left(\mathrm{Na}^{+}+\mathrm{K}^{+}\right)$-ATPase of cardiac sarcolemma. Biochim Biophys Acta 774: 127-137.

LAMERS JMJ, HARTOG JM, VerLOUW PD, HüLSMANN WC (1987) Dietary fatty acids and myocardial function. Basic Res Cardiol 82 (S1): 209-221.

LeAf A, Weber PC (1988) Cardiovascular effects n-3 fatty acids. New Engl J Med 316: 549-557.

McPhail LC, Clayton CC, SNYderman R (1984) A potential second messenger role for unsaturated fatty acids: activation of $\mathrm{Ca}^{2+}$-dependent proteinkinase. Science 224: 622-624.

Medini L, Colli S, Mosconi C, Tremoli E, Galli C (1990) Diets in $n-9, n-6$ and $n-3$ fatty acids differentially affect the generation of inositol phosphates and the thromboxane by stimulated platelets, in the rabbit. Biochem Pharmacol 39: 129-133.

MEIJ JTA, LAMERS JMJ (1989a) Alpha-1-adrenergic stimulation of phosphoinositide breakdown in cultured neonatal rat ventricular myocytes. Mol Cell Biochem 88: 73-75.

MEI JTA, I AMFrs JMJ (1989b) Phorbolester inhibits $\alpha_{1}$-adrenoceptor mediated phosphoinositide breakdown in cardiomyocytes. J Mol Cell Cardiol 21: 661-668.

MEij JTA, Bordoni A, Dekkers DHW, GuARnieri C, LAMERS JMJ (1990) Alterations in polyunsaturated fatty acid composition of cardiac membrane phospholipids and $\alpha_{1}$ adrenoceptor mediated phosphatidylinositol turnover. Cardiovasc Res 24: 94-101.

Montfoort a, Van der Werf L, Hartog JM, Hugenholtz PG, Verdouw PD, hülsmann WC, LAMERs JMJ (1986) The influence of fish oil diet and norepinephrine treatment on fatty acid composition of rat heart phospholipids and the positional fatty acid distribution in phosphatidylethanolamine. Basic Res Cardiol 81: 289-302.

MORRISON WR, SMITH LM (1964) Preparation of fatty methylesters and dimethylacetals from lipids with boron fluoride-methanol. J Lipid Res 5: 600-608.

Nalbone G, Grynberg A, Chevalier A, Leonardi J, Termine E, Lafont H (1990) Phospholipase A activity of cultured rat ventricular myocyte is affected by the nature of cellular polyunsaturated fatty acids. Lipids 25: $301-306$. Post JA, Langer GA, OP Den Kamp JAF, VerkleIJ AJ (1988) Phospholipid asymmetry in cardiac sarcolemma. Analysis of intact cells and "gas dissected membranes". Biochim Biophys Acta 913: 256-266.

ReIBel DK, Holahan MA, HoCK CE (1988) Effects of dietary fish oil on cardiac responsiveness to adrenoceptor stimulation. Am J Physiol 254: H494-H499.

SPECTOR AA, MATHER SN, KADUCE TL, HyMAN BT (1981) Lipid nutrition and metabolism of cultured mammalian cells. Progr Lipid Res 19: 155-186.

STAM H, SChOONDER WOERD GC, HuLSMANN WC (1987) Synthesis, storage and degradation of myocardial triglycerides. Basic Res Cardiol 82 (Suppl. 1): 19-28.

YAGev S, Heller M, PINSON A (1984) Changes in cytoplasmic and lysosomal enzyme activities in cultured rat heart cells: the relationship to cell differentiation and cell population in culture. In vitro 20: 893-898. 